\title{
Tecnologia Social, Universidade e Sociedade: a Extensão como Espaço Estratégico de Intervenção
}

\author{
Social Technology, University and Society: The Extension Space as Strategic Policy
}

Edson Marques Oliveira ${ }^{1}$

Artigo recebido para publicação em Ago/2013 e aceito para publicação em Set/2013.

\section{RESUMO}

Partindo da hipótese de que as universidades, através das atividades de extensão, possam ser espaços estratégicos para geração e reaplicação de novas tecnologias sociais, realizamos uma pesquisa exploratória e um estudo de caso na UNIOESTE, junto aos coordenadores de programas e projetos de extensão, procurando captar as características de empreendedorismo social e tecnologia social nessas atividades de extensão. De 27 programas e 208 projetos de extensão registrados, 11 coordenadores de programas e 86 coordenadores de projetos foram entrevistados, onde $40 \%$ dos projetos de extensão se caracterizam totalmente como empreendedorismo social e $46 \%$ como sendo uma tecnologia social, o que é reforçado com o cruzamento de outros dados. Concluímos que a universidade, a partir da extensão, se mostra como um espaço estratégico na geração de inovação social, incubação e reaplicação de novas tecnologias sociais e futuras políticas sociais mais eficiência e eficácia.

Palavras-chave: Tecnologia social. Empreendedorismo social. Extensão universitária.

\begin{abstract}
Assuming that universities, through extension activities, can be strategic spaces for the generation and replication of new social technologies, we conducted an exploratory survey and case study in UNIOESTE, together with program coordinators and extension projects, looking capture the characteristics of social entrepreneurship and social technology in these outreach activities. 27 programs and 208 extension projects registered, 11 program coordinators and project coordinators were 86 respondents, where $40 \%$ of extension projects are characterized as fully social entrepreneurship and $46 \%$ as a social technology, which is reinforced with crossing other data. We conclude that the university, from the extension, shown as a strategic space in the generation of social innovation, incubation, and application of new technologies and social future social policies more efficiently and effectively.
\end{abstract}

Keywords: Social technology. Social entrepreneurship. University extension.

\footnotetext{
${ }^{1}$ Doutor em Serviço Social pela UNESP, Mestre em Serviço Social pela PUC SP, graduado em Serviço Social pela Faculdade Paulista de Serviço Social de SP. Professor Associado da Unioeste, campus de Toledo, PR, curso de Serviço Social, coordenador Programa Casulo Sócio-Tencológico, membro do GEPEC Grupo de Estudos e Pesquisa em Economia e Desenvolvimento, pesquisas sobre gestão social, inovação e sustentabilidade, ênfase em gestão de empreendimentos sociais solidários e novas tecnológicas sociais sustentáveis e processos de incubação. Vencedor Prêmio Ethos/Valor edição 2007. E-mail: empreendedorsocial03@yahoo.com.br
} 


\section{INTRODUÇÃO}

No contexto neoliberal, vivido com maior ênfase no final dos anos de $1980 \mathrm{e}$ toda década de 1990, foi explicito que o corte no investimento e participação do Estado, sendo essa a principal característica dessa modelo político, onde a redução, principalmente no campo das políticas sociais, agravaram o que historicamente vem se perpetuando, a exclusão social, aumento da pobreza, face a crescente concentração de renda e destruição dos recursos naturais e conseqüentes catástrofes, alterando em profundidade os processos migratórios e as relações de territorialidade e do mundo e mercado de trabalho e na concepção das políticas sociais (Demo, 1996 e Faleiros, 1990).

No Brasil, e em específico 1930 e 1960, a conjuntura da crise condicionou o governo, na época em plena era Vargas, a implementar encargos, além de fomentar o desenvolvimento de instituições de políticas sociais para administrar a questão do trabalho. Dessa época em diante, percebe-se que o tom de desenvolvimento das políticas está estritamente relacionado à questão macroeconômica, vindo a ser relativamente alterada mais recentemente nos dois mandatos do presidente Lula, mas que ainda carece de maior aprofundamento e inovação.

\section{DIMENSÕES DA INOVAÇÃO NO CAMPO SOCIAL}

Com a crescente crise neoliberal e dos caminhos tomados para construção das políticas sociais, nota-se que emerge no epicentro desse processo paradoxal, várias alternativas e notadamente reforçadas pela redução do estado no investimento social, e crescimento da participação das organizações do terceiro setor e sua parceria com ações do segundo setor.

As empresas, por sua vez, e através dos programas de responsabilidade social e sustentabilidade, começam a influenciar o modo da gestão das organizações do terceiro setor, principalmente no que diz respeito temos denominado de lógica sócio empreendedora, onde surge o empreendedorismo social, como sendo um processo, um paradigma e uma estratégia de gestão social 
para gerar inovações social e conseqüentemente, novas tecnologias e empreendimentos sociais. (Cf. Oliveira, 2008)

Com isso, verificamos que o foco não é mais pensar na gestão social, mas sim a gestão do social, ou seja, a gestão das interações humanas e institucionais assim entrou no campo da inovação social. Na área privado, inovação é um conceito amplamente difundido, e esta relacionado à capacidade de inovação da produção e de resultados significativos, em outros termos, inovar é encontrar novas soluções técnicas de como resolver problemas como custo, desperdício, baixos ganhos, alto investimento, o que não se restringe ao campo da produção mas também e principalmente das políticas públicas.

Mas no campo social, a questão da exige uma maior criatividade no tocante a busca de alternativas, de baixo custo e alto impacto, maior socialização dos ganhos, e efetividade da democracia, cidadania e qualidade de vida de todos os cidadãos, e não só de alguns. É desse processo que vemos emergir várias alternativas, que sem dúvida, primam pela emancipação, entre elas destacamos: empreendedorismo social, tecnologias sociais, microcrédito, economia solidaria, entre outros.

Logo, queremos aqui destacar o entendimento de que o empreendedorismo social é visto e entendido como processo emancipatório de ações coordenadas e intencionalmente planejadas, confins de gerar inovação, emancipação e desenvolvimento sustentável, pode e deve gerar novas tecnologias sociais, e o principal, como o foco é no sujeito, e sua participação no processo (empreendedorismo social) e nos resultados (tecnologia social) tendo como pressuposto as características: ser uma ação inovadora, barata, de fácil aplicação, de alto impacto e sendo replicável e transformada em política, tais elementos e compreensão são frutos do trabalho de pesquisa no doutorado, onde ao analisar em profundidade casos práticos e proposições teóricas pudemos chegar a essas conclusões e que serem sinalizadas mais a frente em nosso trabalho. (OLIVEIRA, 2004 e 2008) 


\section{TECNOLOGIA CONVENCIONAL E TECNOLOGIA SOCIAL}

O primeiro ponto, para melhor clarear o nosso entendimento sobre tecnologia social (TS) para fins e propósitos estabelecidos para este estudo, é preciso diferenciar tecnologia convencional e tecnologia não convencional. Por tecnologia convencional, podemos entender as tecnologias que são desenvolvidas pelas áreas de ciência e tecnologia e quem tem uma produção voltada para as necessidades de mercado. Nesse sentido, tecnologia seria uma forma de assegurar a dinâmica de mecanismos de produção de ferramentas, artefatos e processos complexos.

Segundo a Unesco, tecnologia é "[...] o conjunto de conhecimentos científicos ou empíricos diretamente aplicáveis à produção ou melhoria de bens ou serviços" (UNESCO, 2009), o que reforça o primeiro entendimento. Já as tecnologias não convencionais podem ser entendidas como as que apresentam uma lógica e sistematização, mas necessariamente não são voltados para as demandas de mercado e que não seguem padrões pré-determinados.

A tecnologia social (TS) é uma dessas tecnologias não convencionais, por não estar restrita à lógica de mercado, mas focada na dimensão do impacto social e envolvimento e participação direta das pessoas envolvidas e beneficiadas, tanto na elaboração como no uso dessa tecnologia.

Para os fins aqui propostos, usaremos o conceito de TS que mais tem sido difundida aqui no Brasil, entendendo que a mesma está em construção, mas é possível na atualidade é encontrar algumas variações e proposições, vejamos algumas.

Conjunto de técnicas, metodologias transformadoras, desenvolvidas e/ou aplicadas na interação com a população e apropriadas por ela, que representam soluções para inclusão social e melhoria das condições de vida" (INSTITUTO DE TECNOLOGIA SOCIAL, $<$ www.institutodetecnologiasocial.org.br acesso em 20/05/2009)

"Produtos, técnicas e/ou metodologias reaplicáveis, desenvolvidas na interação com a comunidade e que representam efetivas soluções de transformação social" (REDE DE TECNOLOGIA SOCIAL, <www.rts.org.br acesso em 20/05/2009)

É uma denominação que vem sendo politicamente construída, abrangendo um conjunto de referências críticas às tecnologias convencionais [...]. A tecnologia social contrapõe-se a essa lógica, atuando a partir de espaços e práticas que articulam saberes definem táticas cotidianas de resistência das classes trabalhadoras (VARANDA; BOCAYUVA, 2009, p. 24). 
"[...] é compreendido como um conjunto de soluções sociotécnicas para um determinado problema de natureza também sociotécnica" (DIA; NOVAES, 2009, p. 57).

"[...] resultado da ação de um coletivo de produtos sobre um processo de trabalho que produz uma modificação no produto gerando possível de ser apropriado segundo a decisão do coletivo (DAGNINO, 2009, p. 100).

Nota-se que há pequenas diferenças, mas uma centralidade nos conceitos apresentados. Primeiro a nítida contraposição em relação às tecnologias convencionais e sua restrição quanto ao atendimento do mercado e extensivamente aos interesses do capital, da elite e dos interesses políticos, sociais, econômicos e financeiros, indiferentes às necessidades das massas e, principalmente, dos países e dos povos considerados periféricos.

Também pode ser ressaltada a importância que se dá à participação da população e o processo decisório ser na perspectiva do coletivo, da cooperação e da interação entre as partes interessadas. Segundo Tavares (2007), uma das primeiras tecnologias sociais de que se tem notícia é datada de 1924, na Índia, e desenvolvida por Mahatma Gandi, ativista político que buscava alternativas adequadas ao seu povo e à sua cultura para diminuir a pobreza, pois a tecnologia convencional, da época desenvolvida pelo imperialismo Britânico, pouco ou nada resolvia os seus principais problemas, necessitando de tecnologias que fossem mais adequadas a sua realidade cultural.

Essa tecnologia social era chama de Charkha, que popularizou a fiação manual feita em roca de fiar, um movimento que contrapôs uma das principais tecnologias convencionais da época, a fiação mecanizada, desencadeando um movimento de protesto sem violência contra o domínio inglês na Índia. Segundo Tavares (idem), o exemplo de Gandhi é conhecido mundialmente e, em outros países, começam a surgir alternativas e já com a denominação de tecnologia social, como é o caso do alemão Ernest F. Schumacher, que

[...] criou o termo para identificar a utilização de técnicas apropriadas a países pobres. Isso porque, na visão dele, tais procedimentos, além de terem baixo custo operacional e serem de fácil manejo, possuem eficácia na solução de problemas cotidianos e podem ser aplicados com sucesso em outros contextos sociais (TAVARES, 2007, p. 40).

No Brasil, podemos encontrar vários tipos de tecnologias sociais em andamento. Entre elas, um destaque especial são as cisternas, que captam água da chuva e que abastecem de água potável populações que são afetadas pela seca ou falta do acesso de saneamento básico. 
Essa tecnologia social é econômica, de fácil aplicação e replicável como está ocorrendo hoje na região do semi-árido do Brasil, por meio da ação da ONG ASA, que hoje se transformou em uma política pública. Outras tecnologias tem seguido o mesmo rumo, como é o caso do PAIS - Produção Agroecológica Integrada e Sustentável, que alia ações de manejo da terra de forma a gerar alimento, sustentabilidade financeira e preservação do meio ambiente, por focar ações de plantio natural sem o uso de agrotóxicos.

Como podemos perceber nesses exemplos, as tecnologias sociais trazem um teor político e contestatório forte e efetivo, dando ênfase à participação popular e ao empoderamento dos sujeitos de forma a gerar uma consciência coletiva e uma visão de mudo diferenciado, em que ações e projetos bem sucedidos são aplicados em larga escala e até transformados em política pública.

Em nossos estudos sobre o assunto, temos visto certa semelhança do conceito de TS com o conceito e a prática do empreendedorismo social (OLIVEIRA, 2008) e sua relevância para processo de gestão social (OLIVEIRA, 2009).

Para os fins aqui propostos, vamos firmar nossa reflexão e compreensão na perspectiva aqui defendida da Tecnologia Social como sendo uma ação que gera metodologias, processos, serviços e ações que atendam às necessidades dos trabalhadores, privilegiando a sua participação e valorizando a sabedoria popular junto com a sistematização científica, o empoderamento dos sujeitos e a replicação dessas ações para outros contextos e, até mesmo, sugestão de sua aplicação em larga escala e como política social. (Cf. DAGNINO, 2009)

Essa possibilidade de aplicação em larga escala, das Tecnologias Sociais (TS's), sinaliza a possibilidade de transformar as mesmas em política social são extremamente importantes, pois elevam os sujeitos a um patamar de construtores de políticas e não meros consumidores de serviços públicos, o que requer, tanto das organizações como dos profissionais, um preparado adequado para o manejo desse processo.

E estamos defendendo que muitos programas e projetos de extensão podem se caracterizar como tecnologias sócias, logo, as IES, são espaços geradores de novas TS's, que podem influenciar nos rumos e desenhos de políticas sociais, que surgem da integração do conhecimento popular e cientifico. (ARANDA e BOCAYUVA, 2009) 


\section{AS UNIVERSIDADES E A EXTENSÃO COMO ESPAÇO ESTRATÉGICO DE INOVAÇÃO E INTERVENÇÃO SOCIAL E GERAÇÃO DE NOVAS TECNOLOGIAS SOCIAIS}

A partir do entendimento colocado até o momento, e a partir da percepção, tanto teórica como empírica sobre o tema em tela nesse artigo, defendemos que as Instituições de Ensino Superior, (IES) de forma geral, mas principalmente na extensão, são espaços privilegiados para a indução do processo de empreendedorismo social e da geração de novas tecnologias sociais. Com essa percepção e pressuposição, estamos realizando na Unioeste- Universidade Estadual do Oeste do Paraná, na Pró-Reitoria de Extensão um estudo sobre as ações extensionistas, em especifico os programas e projetos. Essa defesa se baseia no modelo multicamp da Unioeste, que abrange duas grandes regiões do Estado do Paraná, Oeste e Sudoeste, atingindo diretamente mais de 70 municípios e uma população de mais de um milhão de pessoas.

Estrategicamente, os campi estão nas principais cidades dessa região: Cascavel, Toledo, Marechal Cândido Rondon, Francisco Beltrão, Foz do Iguaçu, e em processo de aprovação um sexto campus na cidade de Sta. Helena. Segundo dados oficiais da Unioste (Gepec, 2010) a Unioeste tem: 39 cursos de graduação, 66 turmas de graduação, 20 cursos de pós-graduação, sendo que: 17 mestrados, 3 doutorados e 37 especializações, com 9.535 alunos na graduação, 1.051 na pósgraduação, e 1.196 docentes, destes 32 são graduados, 167 especialistas, 513 mestres, 428 doutores e 56 com pós-doutorado. No corpo técnico existem 1.248 profissionais.

\section{CASO DO PROJETO CASULO SÓCIO-TECNOLÓGICO E A CRIAÇÃO DA COPERMESA}

A título de referencia, apresentamos como exemplo de resultado de uma ação com características de empreendedorismo social e que gera novas tecnologias sociais, o Projeto Casulo Sócio tecnológico, do curso de Serviço Social da Unioeste, campus de Toledo, que teve sua principal ação no período de 2004 a 2007. 
O nome Casulo, faz alusão a metáfora da metamorfose da borboleta que tem três fases, a lagarta, o casulo e a borboleta. A primeira fase é o processo de construção de uma ideia inovadora, que sai do papel e é colocado em prática, entra fase casulo, onde é aprimorado, aperfeiçoado e preparado para ser replicado, e entra na terceira fase, a da borboleta. E é tecnológico, pois tem como principio e entendimento que o empreendedorismo social é uma sistematização de ações que buscam fazer algo inovador, diferente para resolver questões de ordem social na perspectiva de empoderamento, capital social e desenvolvimento sustentável, com base na integração de esforços e visão auto construtiva dos espaços e relações sociais (OLIVEIRA, 2004)

Foram elencadas 10 ações, buscando parcerias efetivas que só foram sendo realizadas ao longo da divulgação do projeto aos possíveis parceiros, destacamos duas das ações planejadas. A de Responsabilidade Social Empresarial e Sustentabilidade, tendo como principal parceiro a ACIT - Associação Comercial e Empresarial de Toledo, e a Incubadora de Tecnologia Social, de onde emerge um trabalho com mulheres de um bairro da periferia da cidade de Toledo-PR, o bairro Coopagro a partir de um estudo em uma escola Estadual onde mais $60 \%$ dos alunos são de famílias monoparentais. Necessitando de um trabalho interventivo e que criou o Grupo de Mulheres Empreendedoras Sociais em Ação.

Dessa ação se criou uma metodologia chamada de "Territorialização e mapeamento de oportunidade", A realização do "mapeamento de oportunidades" foi executado em duas fases. A primeira, onde passamos em todas as ruas do bairro Coopagro, na cidade de Toledo-PR, com esses dados fizemos um mapa inteligente, mostrando onde os empreendimentos existentes estão situados e quantos existem de cada tipo de atividade.

A título de exemplificação, inicialmente as mulheres queriam abrir um salão de beleza. No mapa foram encontrados mais 12 salões, o que mostrou uma concentração nessa atividade, o que levou as mulheres e mudarem de ideia. $\mathrm{Na}$ segunda fase, realizamos uma pesquisa domiciliar, e a aplicação de um questionário com 87 questões, com uma amostra de 727 moradores, abrangeu vários tópicos referentes à opinião sobre possíveis serviços e produtos que poderiam ser criado no bairro. Os dados se mostraram confiáveis e úteis. Pois um dos empreendimentos que foram sinalizados, seria a criação de um supermercado mercado, ou uma 
cooperativa de consumo. Mas essa ideia foi descartada decorrente a falta de habilidade e de desejo das mulheres. Mas meses após a pesquisa uma cooperativa foi aberta, e está até hoje em pleno crescimento, o que demonstrou a efetividade da pesquisa.

Por fim foi escolhida pelas mulheres a linha de costura, por que as mulheres em sua maioria tinham experiência e habilidade, além de uma demanda detectada na pesquisa, ou seja, a inexistência de uma organização e de um produto de costura com material reciclado. A coopermesa no ano de 2011 em março fez quatro anos de existência, notamos que as dificuldades são muitas mas é visível um diferencial, estão caminhando com suas próprias pernas, e persistindo no tocante ao processo de maturação do empreendimento, que segundo dados do Sebrae requer no mínimo cinco anos para se consolidar.

Um fator a ser destacado é o processo de escolha a partir de dados da própria realidade em que estão inseridas. O poder público nesse ponto tem um papel vital, sai de uma condição de só prestar serviços assistencialistas, e propiciar condições efetivas para que a própria população alvo das ações públicas possam gerar novas alternativas, interagindo com outros atores sociais.

Isso remente a um novo olhar na elaboração de políticas sociais a exemplo da experiência através da pesquisa de territorialização e mapeamento de oportunidades que resultou na criação da COOPERMESA - Cooperativa de Mulheres Empreendedoras Sociais em Ação). Um projeto que tem caráter/perfil de inovação social. Inovação social que pode ser entendido como novas estratégias que aparecem para suprir as necessidades sociais.

Pois inovação social é um termo que atende desde as condições de trabalho, qualidade de vida até a educação e saúde, podendo ser reaplicado, assumindo assim, sua dimensão de Tecnologia Social, na medida que apresenta um processo metodológico de intervenção social. A título de ilustração, em novembro foi aprovado pelo MEC/Sesu através do edital do PROEXT 2010 recursos para a reaplicação dessa metodologia junto ao grupos de usuários do Programa Bolsa família na cidade de Toledo. 


\section{SOBRE A PESQUISA NA PROEXT DA UNIOESTE E SEUS RESULTADO}

Na Pró-Reitoria de Extensão (Proext) da Unioeste, dados de abril/2011, haviam cadastrados 27 programas, e 208 projetos, 19 cursos, 16 eventos, 12 prestações de serviço, totalizando 282 atividades. Para realizar o estudo de caso, destacamos os principais objetivos e ações desenvolvidas e seus desdobramentos. Da pesquisa, cabe ressaltar alguns aspectos da metodologia adotada. A pesquisa foi planejada em duas fases. Na primeira a aplicação de um formulário eletrônico criado a partir do googledoc, e enviado pelo sistema de e-mail da Unioeste aos coordenadores dos programas e projetos de extensão ativos.

A segunda fase é constituída de uma visita no local de desenvolvimento do programa/projeto, a fim de levantar mais dados empíricos com a observação ativa, além de coletar fotos e depoimentos dos usuários/participantes das atividades, quando possível. Os dados aqui apresentados são da primeira fase. Tais dados preliminares nos mostram a abrangência e capacidade capilar da Unioeste em seu espaço de atuação, e com base nisso, tendo as questões postas na primeira parte desse artigo, é que estamos fazendo um estudo-avaliativo sobre os programas e projetos de extensão, além de analisar quais dessas atividades se caracterizam como sendo de empreendedorismo social e como uma tecnologia social.

O estudo está em andamento, pois estabelecemos como meta, uma amostra de $50 \%$, sendo que até junho de 2011 , foram entrevistas 14 programas, e 104 projetos, o que permite alcançar $78 \%$ e $82 \%$ da meta amostral estabelecida, e cerca de $41 \%$ do total de atividades cadastradas, nesse sentido, são dados que permitem a realização de uma reflexão confiável e significativa dessa realidade e possíveis inferências e comparações com outras realidades. É o que seguir procederemos.

\section{EXTENSÃo COMO ESPAÇO ESTRATÉGICO DE GERAÇÃo DE EMPREENDIMENTOS SOCIAIS E NOVAS TECNOLOGIAS}

Como sinalizado, os dados do questionário, por serem semiestruturados, permitem uma análise ampla de vários fatores estudados, com destaca para alguns dados que nos chamam a atenção, entre eles, o perfil dos coordenadores. Por 
exemplo, em relação ao perfil dos coordenadores, nota-se que $61 \%$ são mulheres, e $39 \%$ são homens, e são pessoas maduras, ficando na faixa etária de 36 a 45 anos, representando cerca de $48 \%$ dos coordenadores, destes $47 \%$ tem doutorado, $37 \%$ mestrado e $14 \%$ são especialistas, apontando outro dado significativo da importância da extensão não só como serviço, mas também como espaço para pesquisa e o ensino, como pode ser comprovado pelos respondentes, onde perguntamos se são elaborados artigos científicos através da atividades de extensão, e cerca de $78 \%$ afirma que sim, e quando perguntamos sobre o resultado final das ações exetensionistas, $49 \%$ dizem ser artigos científicos, seguido de oficinas com $16 \%$ e vídeos com $2 \%$.

Dos que preencheram o formulário eletrônico, $16 \%$ são coordenadores de programas e $84 \%$ de projetos. Além de outros dados, mais de importância avaliativa interna, destacamos duas questões para a reflexão que estamos realizando. Primeiro perguntamos se a atividade poderia ser considerada como sendo de empreendedorismo social, tendo como referência o seguinte parâmetro:

\footnotetext{
É um processo inovador, possui auto impacto e é replicável", e como tecnologia social, tendo como base o conceito da RTS - Rede de Tecnologia Social: "[...] compreende produtos, técnicas ou metodologias que sejam "reaplicáveis", desenvolvidas em "interação com as comunidades" e que representem efetivas soluções de transformação social. (http://revista.fapemig.br/materia.php?id=422, 2005)
}

Logo, resumimos esse parâmetro da seguinte forma: "Fácil de ser realizado, envolve publico alvo a ser atingido, permite gerar auto impacto e retorno a sociedade." Os respondentes deveriam sinalizar em três níveis de caracterização: totalmente, parcialmente, não se caracteriza. Como resultado, vimos que $43 \%$ afirmam que sua atividade se caracteriza como sendo de empreendedorismo social e $47 \%$ como sendo também uma tecnologia social, tendo como principal público sendo atendido, $53 \%$ adultos, seguido de $12 \%$ crianças, $10 \%$ adolescentes, e $24 \%$ outros.

Sobre a equipe ser adequada, $80 \%$ dizem ter uma equipe que possibilidade as ações serem desenvolvidas, destas $24 \%$ tem entre 0 a 2 membros, $22 \%$ de 3 a $5,20 \% 6$ a 8 e somente $14 \%$ de 9 a 10 e 22\% acima de dez, como podemos perceber, equipes pequenas. Como podemos ver, várias atividades de extensão se identificaram como sendo uma Tecnologia Social e de Empreendedorismo Social, a segunda fase da pesquisa, será, verificar se essa percepção, face ao parâmetro 
teórico colocado, se confirmam ou não. Partimos da hipótese de que essa percepção se confirmará, partindo da experiência apresentado, do projeto casulo sóciotecnológico, e do desenho teórico em foco na atualidade sobre Tecnologia Social.

\section{CONCLUSÃO}

Como se pode perceber, os programas e projetos têm um alcance abrangente de ação da extensão no espaço da região Oeste e Sudoeste do Paraná, e mais do que isso, as ações que são ofertadas, tem uma ampla atuação nas áreas de grande necessidade, entre elas: do idoso, da criança e do adolescente, da agricultura familiar, da geração de trabalho e renda, da potencialização das organizações do terceiro setor, da responsabilidade social, do desenvolvimento sustentável, etc.

E ao analisarmos mais detidamente, não só os dados, mas os fatos, a exemplo de atividades que se caracterizam como sendo de empreendedorismo social, como apresentado o caso da Coopermesa, e como sendo uma tecnologia social, podemos perceber como o espaço da extensão e o papel e presença das Universidades é estratégico para a inovação na gestão social.

Também pode ser afirmado que é um espaço que oportuniza a criação de modelos previamente testados e aprimorados (incubados) para serem replicados como políticas públicas, tanto pelo governo local, como estadual e federal, trazendo uma inovação no processo para encontrar ações efetivas de combate a pobreza, a miséria e exclusão social.

Principalmente por colocar os cidadãos como protagonistas e criadores das ações, e não meros usuários de políticas prontas e que não atendam as reais necessidades e desejos da população de interesse, como vem ocorrendo ao longo de nossa história.

Isso demanda para as Universidades e principalmente para o setor de extensão, uma maior sistematização quanto a esse processo, o que poderia ser feito a partir de uma política de extensão que inclua a lógica do empreendedorismo social. 
Bem como, reforçar a perspectiva de gerar novas tecnologias sócias, sustentáveis e replicáveis em larga escala após processo de aprimoramento no âmbito da universidade e relação direta e dinâmica com a sociedade. E com isso, culminar no fortalecimento da relação entre o ensino, a extensão e a pesquisa, e que estejam de fato contribuindo para a materialidade da responsabilidade $e$ compromisso social das universidades.

\section{REFERÊNCIA}

ARANDA, Ana Paula de Moura; BOCAYUVA, Pedro Claudio Cuca. Tecnologia social: autogestão e economia solidária. Rio de Janeiro: Fase, Ippur, Lastro, Ufrj, 2009.

DAGNINO, Renato [et.all]. Tecnologia social: ferramenta para construir outra sociedade. São Paulo: Ig/Unicamp, 2009.

DEMO, Pedro. Política Social, educação e cidadania. 2ed. Campinas, SP: Papirus, 1996.

FALEIROS, Vicente de Paula. Desafios do serviço social na era da globalização. Revista Serviço Social \& Sociedade. n. 61, ano XX. São Paulo: Cortez, 1999. NOVAIS, Henrique T., DIAS, Rafael. Contribuição ao marco analítico-conceitual da tecnologia social.

OLIVEIRA, Edson Marques. Empreendedorismo social: da teoria á prática, do sonho à realidade. Rio de Janeiro: Qualitymark, 2008.

OLIVEIRA, Edson Marques. Gestão e Serviço Social: o empreendedorismo social como estratégia de intervenção. Palmas: Provisão, 2009.

TAVARES, Juliana. Transformação Social. Revista Sociologia/Ciência \& Vida. Ano 1 número 4. São Paulo: Escala, 2007 (p. 38 a 45). 